\title{
Going Beyond the Data: Using Testimonies to Humanize Pedagogy on Black Health
}

\author{
Keisha S. Ray ${ }^{1}$ (D)
}

Accepted: 25 January 2021 / Published online: 12 February 2021

(c) The Author(s), under exclusive licence to Springer Science+Business Media, LLC part of Springer Nature 2021

\begin{abstract}
When health professions learners' primary pedagogical experience of Black people and how they become patients is through statistics, it becomes very easy for learners to think of Black people as data points rather than as individuals whose health is often at the mercy of racist institutions. When the human dimension of Black people's health is ignored, specifically the ways that poor health affects individual wellbeing, one of the barriers to proper health for Black patients is how to be seen and considered as a part of a larger problem of systemic racism and institutional injustices as well as individuals whose personal lives are affected by such larger problems. I propose an approach to health professions pedagogythe experiential race testimonies (ERT) approach - that can change the way health professions learners understand and treat Black patients, thus changing the future of Black health. The ERT approach pairs population data analysis with analysis of personal testimonies and the experiences they convey.
\end{abstract}

Keywords Health education $\cdot$ Pedagogy $\cdot$ Black health $\cdot$ Racial inequities $\cdot$ Racism $\cdot$ Racial disparities

In 1955, James Baldwin wrote in reference to a Black person, "to think of him is to think of statistics, slums, rapes, injustices, remote violence; it is to be confronted with an endless cataloguing of losses, gains, skirmishes" (25). Although Baldwin was not speaking about health professions education, it too has adopted a narrative of Black people represented as statistics, as people who face injustices rather than as complex humans upon whom injustices have been imposed. Specifically, in the health professions, learners are often taught to view Black people through the lens of statistical data representing disparate rates of disease and disorders. This view, however, leaves out the full story behind Black health.

When health professions learners' primary pedagogical experience of Black patients is through statistics, it becomes very easy for them to think of Black people as data points rather than as individuals whose health is often at the mercy of racist institutions. A recitation of endless statistics removes the human dimension of Black people's lesser health

Keisha S. Ray

keisha.s.ray@uth.tmc.edu

1 University of Texas Health Science Center at Houston, McGovern Medical School, McGovern Center for Humanities and Ethics, 6431 Fannin Street, JJL 450, Houston, TX 77030, USA 
outcomes (Hoberman 2012), such as their higher mortality rates from COVID-19 ("The COVID Racial Data Tracker" 2020), higher rates of certain cancers, including breast cancer (Curtis, Quale, and Haggstrom 2008; Haas, Earle, and Orav 2008; Silber, Rosenbaum, and Clark 2013; Ward, Jemal, and Cokkinides 2004), higher maternal mortality rates (Amankwaa, Records, and Kenner 2018; Krisberg 2019), and their general unjust treatment in healthcare systems (U.S. Department of Health and Human Services 1985). When the human dimension of Black people's health is ignored, specifically the ways that poor health affects individual wellbeing, one of the barriers to proper health for Black patients becomes how to be seen and thought of as a part of a larger problem of systemic racism and institutional injustices as well as individuals whose personal lives are affected by these larger problems. One solution to better Black people's health and their relationship with health care is to change the way educators teach health professions learners about their health.

Now that we have data on the lesser status of Black health, as a matter of justice, we have to explore methods of interrogating and ending it. Here, I propose an approach to health professions pedagogy - the experiential race testimonies (ERT) approach-that can change the way health professions learners understand and treat Black patients, changing the future of Black health. The ERT approach is a bi-level pedagogical tool that explores Black health at the population and individual level. It pairs population data analysis with the analysis of personal testimonies and the experiences they convey. Together, the data on Black health and the testimonies from Black patients that attest to their sometimes racially motivated, unjust, and dehumanizing experiences with health care engages learners to explore the totality of Black health. To accomplish the goal of changing the way we educate health professions learners about Black people and what affects their health, the ERT approach 1) centers patients, not their illness or the provider; 2) situates Black patients' experiences with health care within the context of racism; and 3) amoralizes Black people's health. In this article, using examples of testimonies from Black people attesting to their experience of health and health care, as well as the supporting data, I explore the merits of the ERT approach in health professions pedagogy.

\section{Centering the patient, not the illness or provider}

Health narratives or stories about one's experiences with health and health care are already a staple in health humanities, most notably in narrative medicine as described by Rita Charon. Narrative medicine uses health stories to transform the clinical experience for patients and caregivers, namely by using literature and various writing, reading, and listening exercises to help caregivers view patients as whole beings, not just as illnesses. Narrative medicine also helps caregivers examine their own relationship to illness (Charon 2006). Narrative medicine and the ERT approach share at least one goal, which is to provide a more complete picture of the patient. This, however, is generally where the similarities end. For instance, whereas narrative medicine aims to transform the patient-physician relationship as it happens in a clinical setting, the ERT approach aims to transform the way learners think about the lives of Black people before they become patients and how those experiences then mitigate their experience of health and health care once they become patients. The ERT approach also uses testimonies rather than full narratives.

The ERT approach makes Black individuals the center of their experiences of illness and care using their own testimonies, their own words, leaving little room for learners to 
impose their interpretations of what an individual is experiencing. Testimonies are a short, concise, and often times emotionally charged glimpse into the ways in which individuals experience the world. They don't always have a plot and a specific, intended purpose like more formal narratives. More generally, testimonies affirm and allow patients to claim their own experiences, thoughts, or feelings. Testimonies are personal, and when they are shared with others, tellers invite a listener, in this case the health professions learner, into their world as an observer. When Black individuals share their testimonies, they are inviting us to share in their experience of what it means to be Black and ill.

In this sense, testimonies allow passive observation of the ways in which other human being experience the world without imposing judgments on how they ought to experience that world. This is particularly important when testimonies reveal experiences of a world that is very different from our own and therefore perhaps difficult to comprehend. For nonblack learners, because their own social identities do not give them personal access to the ways Black people experience the world, testimonies from Black people allow them to observe the world from another perspective. Being in the observer position allows learners to consider another viewpoint without inserting themselves into Black people's experiences with illness and health care.

Whereas some use of health narratives aims to help healthcare providers understand what they experience in the presence of illness and make them central to narrative exercises, the ERT approach removes the focus of healthcare providers as much as possible. Since most Black patients will have caregivers who are not Black given that in 2018 only $5 \%$ of physicians identified as African-American or Black and in 2017 only $6 \%$ of registered nurses identified as African-American (American Association of Colleges of Nursing 2019; American Association of Medical Colleges 2019), it is imperative for the proper treatment of Black people not to make Whiteness the standard by which Black people's experience of illness is judged. And if not properly educated, it is very easy for White health professions learners to judge Black people's experiences based on their own limited perspective of illness. But given Black people's different experiences with race, including the biological and psychological effects of racism (Clark et al 2013), making whiteness the standard for judging illness means ignoring the unique social context of the Black experience and its influence on health.

The use of testimonies in the ERT approach is similar to the Health Humanities Portrait Approach to curriculum, which centers the patient's own words using illness narratives. The idea behind the Health Humanities Portrait, as a pedagogical tool, is that when patients speak about their experiences, they provide learners with their own experiential expertise about illness and health. Centering the patient also minimizes the chance that learners will objectify patients; instead, patients become more than their illness with full lives outside of their it (Sufian et al. 2020). The ERT approach extends this specifically to Black people who as Baldwin states, too often are viewed only by their losses and the marginalized aspects of being Black rather than as individuals with full lives. Using testimonies from Black people gives them an authority over their own stories in health care, which too often either doesn't trust Black people to be narrators of their own stories or removes their voice from those stories.

The many patient narratives that are coming out of the COVID-19 pandemic provide healthcare professions educators with an abundance of material for the ERT approach. In particular, many testimonies from Black people attests to their unequal experience of the virus, including the ways that social inequities complicate their experience of the pandemic (Yancy 2020). Moreover, we have the data (although incomplete since the pandemic is ongoing) that supports these experiences, completing the ERT approach. 
For instance, as of October 2020, Black individuals are 2.5 times more likely to die COVID-19 infection than White people ("The COVID Racial Data Tracker" 2020). More specifically, in cities like New York City, Black people had a death rate of ninetytwo per 100,000 as compared to forty-five per 100,000 for White people ("Too Many Black Americans are Dying from COVID-19" 2020). Additionally, in the early days of the pandemic, Black people made up 30\% of COVID-19 patients, while only making up $13 \%$ of the population (CDC COVID Data Tracker 2020). Disparate experiences with COVID-19 also extend to Black children as Black (and Latinx children) have overwhelmingly higher rates of hospitalizations for COVID-19 infections than White children (Lindsay et al. 2020).

As the pandemic progresses, Black people, in addition to Latinx and Indigenous people continue to die from COVID-19 at disproportionate rates (Gold et al. 2020; Killerby et al. 2020; Price-Haygood et al. 2020; Millet et al. 2020). The Centers for Disease Control and Prevention (2020) has stated that people from certain racial and ethnic minority groups are at increased risk of infection and death from COVID-19 because of inequities in social determinants of health and factors such as racial discrimination. As the COVID-19 pandemic is an ongoing event and more data continue to be released by public health organizations, universities, and government agencies, we will get a better picture of the impact the virus is having on Black people. However, we do have many stories of Black people's unequal access to care, the structural and institutional barriers they have to overcome to receive care, their experiences with provider bias when seeking care, and the ways that COVID-19 is magnifying their fears of medical mistreatment.

For instance, in the early months of the pandemic, Tanya Fields, a Black woman living in New York, a hot spot at the time, had all of the symptoms of COVID-lethargy, body aches, fever, and cough. Although it was likely that she had COVID-19, Fields chose to recover at home with her family, including her six children because she mistrusts medicine, citing its history of poorly treating Black people: "Black folks don't get treated well in hospitals and so if I can stay at home and get better, if I don't need a prescription from the hospital, why the hell am I going?" (Harper 2020).

Using both the data on COVID-19 and examples of the testimony from individuals like Fields, educators can engage learners in discussions on Black people's historical relationship with health care and its implication for contemporary clinical interactions, specifically for COVID-19 testing and therapies. To spur conversation, educators can ask students: "Why might Fields have this sentiment about hospitals? What about the United States' handling of COVID-19 may have led her to think this way about medicine and about her own health? How might the data on COVID-19 and its effects on Black people influence her decision not to seek treatment?" These are just some of the questions that can prompt learners to reflect on what Fields' testimony reveals about the Black experience of the COVID-19 pandemic.

The ERT approach becomes even more impactful when learners see testimonies that attest to different experiences on the same topic. For instance, when Keith Grambell's father, Gary Fowler, a Black man with diabetes went to a Detroit hospital with COVID19 symptoms, staff refused to test Fowler for the virus and instead sent him home with instructions to take Tylenol. Reflecting on this, Grambell stated that he felt the hospital staff ignored his dad:

It's like a slap and a spit in the face. My dad should have been tested. I just feel like he should have been more of a priority since he's a high-risk candidate to be dead from this virus. But they just pushed him out the door, like he wasn't shit. (Lim 2020) 
Just days after being denied a COVID-19 test, Fowler died in his home. Grambell believed that if his father had been tested and received a positive COVID-19, test he may have been more of a priority for future care, thus saving his life (Lim 2020).

The day that Fowler died, Grambell's mother also began showing signs of COVID-19, including shortness of breath and high fever. Learning from the experience with his father, Grambell rushed his mother to the hospital, but she was also denied a test. Grambell took his mother to another hospital where she was tested, and the results indicated that she was positive for COVID-19. After multiple people in the family received positive COVID-19 tests, including himself, Grambell reflected on why it was so difficult for his family to receive the care they needed:

I'm pretty sure they knew that this was going to attack the Black community like this. So why weren't we better prepared as a country? Just seeing it affect us is crazy. It's mind-blowing. But I kinda know why — we're being pushed home to die. (Lim 2020)

Like Fields' testimony, Grambell's words reveal a lack of faith in medicine's ability to treat Black people fairly - a belief that medicine does not care about Black life. Adding his testimony to Fields' testimony reveals a picture of the virus that the data do not: the individual experience of being Black and living during a pandemic in the $21^{\text {st }}$ century. Together, both Fields and Grambell's testimonies (among others), along with the data on COVID-19 provide educators with opportunities to discuss Black health and Black people's experiences with health care.

\section{Situating Black patients within a context of racism}

In the United States, Black women are three times more likely to die from pregnancyrelated complications when compared to White women ("Racial and Ethnic Disparities Continue in Pregnancy Related Deaths" 2019). In New York, researchers found that even when Black women have a college degree, their chances of dying during or soon after birth are still three times higher than White women who never completed a high school diploma (New York City Department of Health and Mental Hygiene 2016). In the United Kingdom, Black maternal mortality is also a public health concern. In 2016, for every 100,000 deaths during pregnancy, eight White women died compared to forty Black women (Anekwe 2020). Using the available data on Black maternal mortality for context, the ERT approach examines individual instances of Black maternal death and individual instances of racial bias in Black women's birthing stories as a part of a broader systemic problem of racism in medicine and racism in social institutions that create inequities in social determinants of health.

Supporting this approach to Black maternal mortality, the CDC, has argued that racial disparities in maternal mortality cannot be attributed to Black women's greater propensity for death during or soon after pregnancy. Rather, a lack of access within social determinants of health explains Black women's disparate maternal mortality. Additionally, systemic inequalities in health care such as Black women's experiences with providers' racial biases also explains their increased mortality. Specifically, to address Black women's maternal mortality, the CDC recommends that hospitals and healthcare systems "identify and address implicit bias in healthcare that would likely improve patient-provider interactions, health communication, and health outcomes" ("Racial and Ethnic Disparities 
Continue in Pregnancy Related Deaths" 2019). With this recommendation, the CDC affirms that health care needs to address the effects of racism, within and outside of the clinical setting.

Examining the problem of Black maternal mortality requires us to view the problem from within the context of structural racism, specifically racial discrimination of physicians, nurses, lactation specialists, and other caregivers as well as the barriers they create for Black women seeking safe maternal health care. Although the data alone indicate that something other than biology makes Black pregnant and delivering people vulnerable to death, the stories from Black women and their surviving families also indicate racism as the factor that makes a difference in Black maternal mortality. Tobi Oredein, a Black woman, who delivered her child in the United Kingdom provides one of those stories.

Before delivering her child, Tobi Oredein made it a priority to prepare for her interactions with a racist healthcare system. During her sixty hours of labor, she developed a fever. When providers made the decision to begin the process of delivering her baby via $\mathrm{C}$-section, Oredein was put in the hospital corridor to wait. Because she delivered during the COVID-19 pandemic, her husband was not allowed to be with her. When one of the doctors who would be operating on her passed Oredein in the corridor, the doctor looked at her and shouted, "Get this Covid suspect out of here! Why is she here?!" Oredein did not confront the doctor because she feared that a confrontation could jeopardize her life or her baby's life. Reflecting on her birthing experience, Oredein shares other racist encounters that she experienced during her pregnancy and her hopes for how health care will treat Black women in the future:

Despite (thankfully) leaving the hospital with a healthy baby, I want our healthcare system to see Black women as humans, not stereotypes or objects that don't need love and care. I want a healthcare system that asks me what I need, rather than tells me to carry on when I feel like I can't, that shows compassion to Black women when we feel at our weakest.

I want healthcare that doesn't call my husband a 'baby daddy' when we attend a routine checkup in tracksuits. I want healthcare that in times of a pandemic or not, doesn't make me feel like a burden. I want doctors that see the fear on my face and console me. I'm not asking to be wrapped up in cotton wool but I am asking for care. (Oredein 2020)

Oredein pleas for healthcare providers to see her and other birthing Black women like her to be treated with respect and care and not with stereotypes and racial bias. In her testimony, she calls our bias in health care systems.

Along with general discussions on racial bias in medicine, Oredein's testimony, along with the available data on Black women's maternal mortality rates provide the foundation for educators to discuss specifically the effects of racism in and outside of the clinical setting. For instance, educators can discuss how Black people's experiences with racism and microagressions in their everyday lives affect their clinical encounters with providers. Educators can also discuss providers' actions, including ways to improve relationships with Black patients.

Oredein's story is but one of the many stories about Black women experiencing racism during or soon after childbirth that educators can find with a simple search of the literature. Often these stories end differently than Oredein's story-with the mother and/or the baby dying. The ERT approach allows educators to use these stories and many others like them to discuss with learners the impact of racial bias against individual Black birthing people, while the data situate the stories within a broader context of a racist system that 
can be deadly for Black birthing people. The ERT approach helps learners examine the issue of Black maternal mortality as more than a fluke, or something that just happens to a few Black people; rather it reveals it as a systemic problem that is not a normal part of health care. More importantly, the ERT approach shows learners that they are integral to changing this systemic problem. When healthcare professions learners take part in the ERT approach, they are taking steps to change the way providers understand and interact with Black patients, resulting in better care for Black patients and systematic changes in healthcare.

\section{Amoralizing Black health}

Another feature of the ERT approach is that it aims to encourage learners not to think of Black people's behaviors as moral and immoral. Often Black people are blamed for their poor health, judged as immoral for participating in unhealthy behaviors that contribute to their illnesses. For example, in his 2015 memoir entitled, Black Man in a White Coat, Damon Tweedy, a Black physician, tells the story of the patients he treated at a free clinic in a rural part of North Carolina. There he frequently saw Black patients diagnosed with hypertension and diabetes. While reflecting on how he interacted with these patients, he recalls assuming that their poor health was made worse by their poor life choices such as eating fast food or lack of exercise. When he learned that these patients either couldn't afford treatment for their chronic diseases, that their rural town did not have a mainstay physician's office, or that despite making healthy lifestyle choices like not smoking or drinking alcohol, he had to confront his biases. Furthermore, he had to consider that if he could have these biases against Black patients, despite being a Black person himself, could his White colleagues have the same biases against Black patients, could they also see Black patients with poor health as moral failures? When reflecting on the social factors that influenced his Black patients' health, Tweedy is not saying that Black people are never to blame for their poor health, but he is acknowledging that sometimes there are external factors beyond their control that influences their health. And instead of making their decisions a matter of morality, we should view their health decisions within the context of social determinants of health, namely within the social and cultural context in which they live and make decisions about their health.

Using the ERT approach educators can help learners who may be tempted to moralize about Black people's choices like Tweedy. Testimonies, in particular, can help learners think about the social and cultural context of their health and the decisions they make for their health. For example, Donald Owens, a fifty-two-year-old Black man reflects on what led to his diabetes diagnosis:

I think I acquired the diabetes, not that it is hereditary, but I acquired it through eating what my parents ate.... They used to eat like so many starches all the time, so many beans, so many sweet potatoes, chicken breasts, chicken fried, and we used to eat a lot of fried foods all the time.... sneaking in when I was a kid, sneaking in to make so many sugar sandwiches. Sugar and butter sandwiches, full of sugar like that thick, and I think that is really what got to me. (Liburd et al. 2004, 222)

Owens is one of the Black adults who is at a higher risk to develop diabetes than White adults based on biological and social risk factors (Hicklin 2018). In his testimony, Owens acknowledges the social factors that he believes contributed to his diagnosis. 
Similarly, Darnell, a forty-year-old Black man diagnosed with coronary heart disease reflects on how his learned, cultural behavior contributed to that diagnosis:

I know that before I had heart disease, I was eating pork all the time! Ribs? You couldn't get me out of a rib place—bacon, pork chops, you know. And that could be bad for you...It's probably a primary cause. From what I understand of the history, we started off being slaves. We ate what we can and throughout time it just became a delicacy for us, making meals out of what we can. My parents are from New Orleans. It kind of [got] picked up from them what I thought was good food not realizing it was bad. (Dubbin, McLemore, and Shim 2017)

Like Owens, Black Americans have higher rates of mortality from cardiovascular disease than White Americans. It is estimated that $48 \%$ of all Black men and $44 \%$ of all Black women have some form of heart disease including hypertension (Cleveland Clinic 2017). Like Owens, Darnell believes that his eating habits contributed to his diagnosis.

Testimonies from Black individuals like Owens and Darnell humanize statistics about the disparity in the Black population of diabetes and cardiovascular disease; they put a face to the numbers that can easily become meaningless for learners. Using the ERT approach, the testimonies and data on diabetes and cardiovascular disease, as just an example, help students view Black people's experience with disease as a matter of social and biological factors that are either outside of their control and therefore, ought not to be judged, or as behaviors that are cultural and could be amended with providers' guidance. The ERT approach encourages learners to think about their role in educating their Black patients on healthy lifestyle choices given certain cultural practices and using cultural competency when treating Black patients rather than declaring their lifestyle choices as "bad" or "immoral."

\section{Limitations}

The kind of racial discrimination that Black people experience is unique to the experience of being Black, yet so interwoven into the experience of being Black that not even a powerful testimony can make someone understand what it feels like to experience discrimination, poor health, and mistreatment because of false socio-political narratives attached to skin color. Since non-Black people can never have first-hand access to the experience of being Black, the freeform, short nature of testimonies that the ERT approach uses may not be enough to accomplish its goals. Therefore, empathy is not the goal of the ERT approach; rather understanding, connectedness, and action are the intended goals. Some learners, particularly those resistant to the ERT approach and those hostile to learning about Black health may need more substantial narratives that provide more information to connect to the experience being conveyed by the individual. Learners may find testimonies impersonal and not enough to supplement the information conveyed by data.

Learners who are hostile to learning about Black health may find the three merits of the ERT approach I've discussed in this article unconvincing. For instance, learners who do not believe that racism exists nor that Black people face any significant racial biases in health care may be resistant to examining Black patients within the context of racism. Similarly, learners who think that Black people have full control over their health and that their poor health is the result of bad choices will not be convinced. The ERT approach may initially work best for learners who are already sympathetic to bettering the status of Black 
people's health but can also reach learners who resist its methods by presenting both the factual story and the human story of Black health.

\section{Conclusion}

The ERT approach pairs data with testimonies for an all-encompassing learning experience for future caregivers, giving them the information to situate Black health within a larger social context and showing the impact poor health can have on Black individuals and their families. It aims to give Black people a voice and to show that the problems that affect their health are bigger than an isolated problem. Instead of individual changes, larger systemic changes must occur for better Black health, and that starts with how we educate learners.

The ERT approach gives health humanities educators an opportunity to expand the way that learners study about Black individuals and the Black population, a group of people made vulnerable by systemic injustices, including those that occur in medicine. As future caregivers, learners can use the ERT approach to better understand the features of Black people's lives and better understand needs of Black people while they are seeking care. Education is one of the best ways to better Black health and correct their disparate health outcomes and the ERT approach does just this; it educates while humanizing Black people and showing the unjust nature of their poor health outcomes and healthcare.

\section{References}

American Association of Colleges of Nursing. 2019. "Enhancing Diversity in the Workforce." Accessed 28 August 2020. https://www.aacnnursing.org/News-Information/Fact-Sheets/Enhancing-Diversity.

American Association of Medical Colleges. 2019. "Diversity in Medicine: Facts and Figures 2019." Accessed 28 August 2020. https://www.aamc.org/data-reports/workforce/interactive-data/figur e-18-percentage-all-active-physicians-race/ethnicity-2018.

Amankwaa, Linda C., Kathie Records, and Carole Kenner. 2018. "African-American Mothers' Persistent Excessive Maternal Death Rates.” Nursing Outlook 66 (3): 316-318.

Anekwe, Lilian. 2020. "Ethnic Disparities in Maternal Care." The BMJ 368: m442.

Baldwin, James. 1955. Notes of a Native Son. Boston: Beacon Press.

CDC Covid Data Tracker. 2020. "Demographic Trends of COVID-19 Cases and Deaths in the US Reported to CDC." Accessed 28 August 2020. https://covid.cdc.gov/covid-data-tracker/\#demog raphics.

Charon, Rita. 2006. "Narrative and Medicine." New England Journal of Medicine 350 (9): 862-864.

Clark, Rodney, Norman B. Anderson, Vernessa R. Clark, et al. 2013. "Racism as a Stressor for African Americans: A Biopsychosocial Model." In Race, Ethnicity, and Health: A Public Health Reader, edited by T. A. LaVeist and L. A. Isaac, 79-103). Jossey-Bass/Wiley.

Cleveland Clinic. 2017. "Heart Disease: Reducing Risks for African-Americans." Accessed 1 October 2020. https://health.clevelandclinic.org/heart-disease-reducing-risks-for-african-americans/.

The COVID Racial Data Tracker. 2020. The Atlantic. Accessed 24 August 2020. https://covidtracking. com/race.

Curtis, Elana, Chris Quale, and David Haggstrom. 2008. "Racial and Ethnic Differences in Breast Cancer Survival: How much is Explained by Screening, Tumor Severity, Biology, Treatment, Comorbidities, and Demographics?" Cancer 112 (1): 171-180.

Dubbin, Leslie, Monica McLemore, and Janet K. Shim. 2017. "Illness Narratives of African Americans Living with Coronary Heart Disease: A Critical Interactionist Analysis." Qualitative Health Research 27 (4): 497-508.

Gold, Jeremy A., Karen K. Wong, Christine M. Szablewski, et al. 2020. "Characteristics and Clinical Outcomes of Adult Patients Hospitalized with COVID-19 — Georgia, March 2020.” Morbidity and Mortality Weekly Report 69 (18): 545-550. 
Haas, Jennifer S., Craig C. Earle, and John E. Orav. 2008. "Racial Segregation and Disparities in Breast Cancer Care and Mortality. Cancer 113 (8): 2166-2172.

Harper, Averi. 2020. "COVID-19 Exposes Mistrust, Health Care Inequality going back Generations for African Americans.” ABC News. Accessed 31 August 2020. https://abcnews.go.com/Health/covid -19-exposes-mistrust-health-care-inequality-back/story?id=70370949.

Hicklin, Tiana. 2018. "Factors Contributing to Higher Incidence of Diabetes for Black Americans." National Institute of Health. Accessed 1 October 2020. https://www.nih.gov/news-events/nih-resea rch-matters/factors-contributing-higher-incidence-diabetes-black-americans.

Hoberman, John. 2012. Black and Blue: The Origins and Consequences of Medical Racism. Los Angeles: University of California Press.

Katersby, Aaron and Ella Torres. 2020. "Black People in NYC Twice as Likely to Die from COVID as White People: Data." ABC News. Accessed 31 August 2020. https://abcnews.go.com/US/black -people-nyc-die-covid-white-people-data/story?id=70208362.

Killerby, Marie, Ruth Link-Gelles, and Sarah C. Haight, et al. 2020. "Characteristics Associated with Hospitalization among Patients with COVID-19 - Metropolitan Atlanta, Georgia, March-April 2020." Mortality and Morbidity Weekly Report 69 (25): 790-794.

Krisberg, Kim. 2019. "Maternal Death Rates High for Black Women." American Journal of Public Health 109 (10): 1311.

Liburd, Leandris C., Apophia Namageyo-Funa, Leonard Jack, et al. 2004. "Views from Within and Beyond: Illness Narratives of African-American Men with Type 2 Diabetes." Diabetes Spectrum 17 (4): 219-224.

Lindsay, Kim, Michael Whitaker, Alissa O’Halloran, et al. 2020. "Hospitalization Rates and Characteristics of Children Aged < 18 years Hospitalized with Laboratory-confirmed COVID-19 - COVID-NET, 14 States, March 1-July 25, 2020." Morbidity and Mortality Weekly Report 69 (32):1081-1088.

Lim, Clarissa-Jan. 2020. "His Dad was Denied a Coronavirus Test by Three Hospitals and Died. He wasn't Going to let that Happen to his Mom too." Buzzfeed News. Accessed 31 August 2020. https ://www.buzzfeednews.com/article/clarissajanlim/fowler-family-detroit-coronavirus-black-ameri cans-testing.

Millet, Gregorio A., Austin T. Jones, David Benkeser, et al. "Assessing Differential Impacts of COVID19 on Black Communities." Annals of Epidemiology 47:37-44.

New York City Department of Health and Mental Hygiene. 2016. "Severe Maternal Morbidity in New York City, 2008-2012.” https://www1.nyc.gov/assets/doh/downloads/pdf/data/maternal-morbidityreport-08-12.pdf.

Oredein, Tobi. 2020. "I'm a Black Mum who gave Birth during COVID-19. I've Never Felt More Vulnerable." Accessed 10 August 2020. https://www.huffingtonpost.co.uk/entry/im-a-black-mum-whogave-birth-during-covid-19_uk_5f2d351dc5b6e96a22b157d6?utm_campaign=hp_fb_pages\&utm_ medium =facebook\&utm_source=bv_fb\&ncid=fcbklnkushpmg00000047\&fbclid=IwAR17FrJx 8TE3OW8uYDYiq_cw8ISizTJLzvGPTekZAAnwW0q5qeFj99LQUOA\&guccounter=1\&guce_ referrer=aHR0cHM6Ly9sLmZhY2Vib29rLmNvbS8\&guce_referrer_sig=AQAAAKIoL5k-tCPYA L_RzhCI6YcK292mVqwDeMYMFe3wU0OAE68yP8OhRyVcTwMbGfdEJJCHXmPq09zJ5H7cJ2pO0Aduxia47P0vWTEfy-obuKSg7TYyfCgiAA6mlqdJfybs3uuAdRyYbrj-TMbxBkH4bR 131TXeF43MvZTMZXb1vy4.

Price-Haygood Eboni G., Jeffrey Burton, Daniel Fort D, et al. 2020. "Hospitalization and Mortality among Black Patients and White Patients with Covid-19." New England Journal of Medicine 382:2534-2543.

"Racial and Ethnic Disparities Continue in Pregnancy Related Deaths." 2019. Centers for Disease Control and Prevention. Accessed 31 August 2020. https://www.cdc.gov/media/releases/2019/p0905 -racial-ethnic-disparities-pregnancy-deaths.html.

Silber, Jeffrey H., Paul R. Rosenbaum, and Amy S. Clark. 2013. "Characteristics Associated with Differences in Survival among Black and White Women with Breast Cancer." Journal of the American Medical Association 310 (4): 389-397.

Sufian, Sandy, Michael Blackie, Joanna Michel, et al. 2020. "Centering Patients, Revealing Structures: The Health Humanities Portrait Approach." Journal of Medical Humanities. https://doi. org/10.1007/s10912-020-09640-8.

“Too Many Black Americans Are Dying from COVID-19." 2020. Scientific American. Accessed 28 August 2020. https://www.scientificamerican.com/article/too-many-black-americans-are-dying -from-covid-19/.

Tweedy, Damon. 2015. Black Man in a White Coat. New York: Picador. 
U.S. Department of Health and Human Services. 1985. "Report of the Secretary's Task Force on Black and Minority Health.” Washington, D.C. Accessed 28 August 2020. https://collections.nlm.nih.gov/ catalog/nlm:nlmuid-8602912-mvset,

Ward, Elizabeth, Ahmedin Jemal, and Vilma Cokkinides. 2004. "Cancer Disparities by Race/Ethnicity and Socioeconomic Status." CA: A Cancer Journal for Clinicians 54 (2):78-93.

Yancy, Clyde W. 2020. "COVID-19 and African Americans." Journal of the American Medical Association 323 (19): 1891-1892.

Publisher's Note Springer Nature remains neutral with regard to jurisdictional claims in published maps and institutional affiliations. 